patients: role of fluid retention and nocturnal rostral fluid shift. J Hum Hypertens. 2015;29:34250. DOI: 10.1038/jhh.2014.94

7.Briancon-Marjollet A, Weiszenstein $\mathrm{M}$, Henri M, Thomas A, Godin-Ribuot D and PolakJ. The impact of sleep disorders on glucose metabolism: endocrine and molecular mechanisms. Diabetol Metab Syndr. 2015;7:25. DOI: 10.1186/s13098-015-0018-3

8 .Logan AG, Perlikowski SM, Mente A, Tisler A, Tkacova R, Niroumand M, Leung RS and Bradley TD. High prevalence of unrecognized sleep apnoea in drug-resistant hypertension. J Hypertens. 2001;19:2271-7. DOI: 10.1097/00004872-200112000-00022

9.Bratton DJ, Gaisl T, Wons AM and Kohler M. CPAP vs Mandibular Advancement Devices and Blood
Pressure in Patients With Obstructive Sleep Apnea: A Systematic Review and Meta-analysis. JAMA. 2015;314:2280-93. DOI: 10.1001/jama.2015.16303

10.Becker HF, Jerrentrup A, Ploch T, Grote L, Penzel T, Sullivan CE and Peter JH. Effect of nasal continuous positive airway pressure treatment on blood pressure in patients with obstructive sleep apnea. Circulation. 2003;107:68-73. DOI: 10.1161/01.cir.0000042706.47107.7a

11.Cuspidi C, Tadic M, Sala C, Gherbesi E, Grassi $G$ and Mancia G. Obstructive sleep apnoea syndrome and left ventricular hypertrophy: a meta-analysis of echocardiographic studies. J Hypertens. 2020;38:1640-1649. DOI: 10.1097/ $\mathrm{HJH} .0000000000002435$

FULL REFERENCE LIST

\title{
Obstructive Sleep Apnea Management in Patients with Cardiovascular Comorbidities
}

\section{DOMINIK LINZ}

Department of Cardiology, Maastricht University Medical Centre and Cardiovascular Research Institute Maastricht,

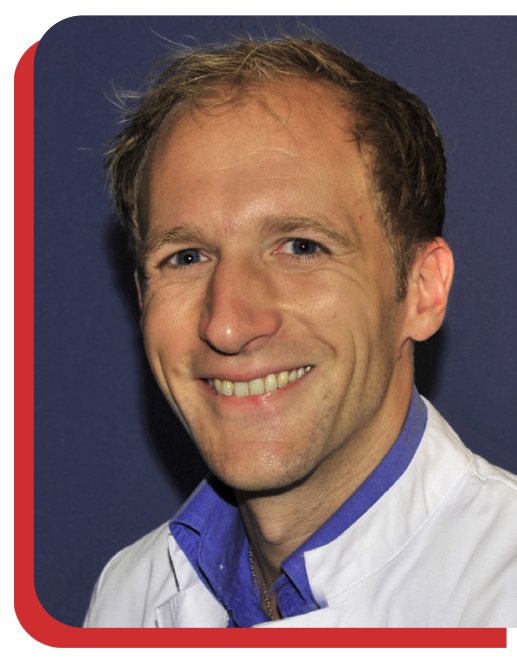

Maastricht, The Netherlands.

DOI:10.30824/2106-15

Obstructive sleep apnea (OSA) is highly prevalent in patients with cardiovascular (CV) comorbidities such as hypertension or atrial fibrillation and is associated with increased risk of mortality, CV events and arrhythmias. ${ }^{1}$ Continuous positive airway pressure (CPAP) is established as first line therapy in OSA patients with moderate or severe OSA due to its impact on both symptoms and quality of life. In clinical care, CPAP is recommended to be combined with lifestyle changes and weight loss.

Up to $50 \%$ of OSA patients may have hypertension, and $30 \%$ of hypertensive patients will likely have OSA. ${ }^{2}$ Patients with untreated OSA followed over 4 years have a 2-3 fold increased risk of developing incident hypertension, independent of the usual risk factors for hypertension. ${ }^{2}$ Metaanalyses of randomized trials of CPAP in patients with hypertension have reported modest blood pressure decreases of between 2 to $3 \mathrm{mmHg} .{ }^{3}$ In patients with atrial fibrillation, the prevalence of OSA in patients with AF is higher (21-74\%) than in controls without AF (3-49\%). ${ }^{4}$ In a meta-analyses of several non-randomized studies, the use of CPAP was associated with a $42 \%$ decreased risk of AF-recurrence. ${ }^{5}$ Randomized studies in the field of atrial fibrillation management are currently ongoing.

Three randomized controlled trials assessed the effects of CPAP on secondary prevention of CV events (Table). The Sleep Apnea Cardiovascular Endpoints (SAVE) trial randomised over 2000 
patients with established CV disease or cerebrovascular disease to CPAP plus usual care, or usual care alone. ${ }^{6}$ The use of CPAP (over a mean follow-up of 43 months) did not significantly reduce the primary composite endpoint of major adverse cardiac events, although sleepiness did improve. In a pre-specified subgroup analysis, those with CPAP adherence $>4 \mathrm{hrs} /$ night had a lower risk of stroke (HR $0.56 \mathrm{Cl} 95 \%$ 0.32-1.00) and total cerebrovascular events (HR 0.52 95\% $\mathrm{Cl}$ 0.30-0.90).

In the RICCADSA trial, patients with moderate or severe OSA (but with no daytime sleepiness) were randomised to CPAP or control after coronary revascularisation, and followed up for a mean of 57 months. ${ }^{7}$ The CPAP group showed no change in CV endpoints including repeat revascularisation, although the subgroup using CPAP $>4 \mathrm{hrs} / \mathrm{night}$ had a lower CV risk (HR 0.29 95\% CI 0.10-0.86).

A further study (ISAACC trial) examined patients with acute coronary syndrome and moderate or severe OSA. ${ }^{8}$ CPAP had no significant effect on the primary composite endpoint of CVD events or death. In this trial there was no relationship between hours of CPAP use and outcomes, but the adherence to CPAP was low at $2.78 \mathrm{hrs} / \mathrm{night}$.

The reasons for these randomised trials failing to demonstrate CV benefit has been debated. The consensus was, that a better phenotyping of sleep apnea is required. Patients with a similar apnea hypopnea index have widely different combinations of abnormalities in airways anatomy, neuromuscular responsiveness, respiratory chemosensitivity and loop gain. Poor compliance with airways pressure support in patients with no excessive daytime sleepiness may also bias randomised trials to find no effect of intervention. Another limitation in carrying out randomized controlled trials with cardiac endpoints in OSA is that patients with severe sleepiness or hypoxemia -the groups who might benefit the most from treatment - were often excluded because of ethical reasons. Additionally, CPAP tolerance remains a key issue in interpreting results.

Despite the absence of a clear evidence that OSA treatment prevents CV events in secondary prevention, current guidelines for the management of hypertension and atrial fibrillation recommend testing for and treating OSA to improve hypertension and rhythm control..$^{8,9}$ Attended inhospital polysomnography is the gold standard test for OSA. However, as shown by a recent survey by the European Heart Rhythm Association (EHRA) and the Association of Cardiovascular Nurses and Allied Professions (ACNAP), structured testing for OSA only occurs in the minority of patients due to the fact that access to polysomnography in a sleep laboratory as well as the reference method for OSA diagnosis is limited due to long waiting lists, high labor intensity and high costs. ${ }^{10}$

Home Sleep Apnea Test (HSAT) with oxygen saturation and other respiratory measures is more widely available, can be set-up by the patient at home and have shown to be an inexpensive, reliable and sensitive alternative technologies to polysomnography in a sleep laboratory. To prevent fragmentation of care, a structured OSA testing and management pathway can be implemented in a specialized hypertension or AF clinic with a holistic approach. An integrated pathway for OSA testing and management has been proposed previously and could be embedded in a specialized outpatient clinic. Interdisciplinary collaboration between the sleep specialist, cardiologist/nephrologist and specialized nurses is crucial to coordinate the care and to assure that patients will be tested for OSA (Figure). In the case of a positive test result showing moderate-to-severe obstructive OSA (apnea-hypopnea index $\geq 15 / h$ with predominant obstructive respiratory events), the referral to the sleep clinic for CPAP initiation and titration as well as the structured long-term follow-up should be integrated in the usual care pathways in AFclinics. First, CPAP treatment should always be combined with weight loss interventions if needed and lifestyle modification (e.g. alcohol avoidance, sleep hygiene, etc.) as important components of risk factor management programs, which have been shown to improve both, OSA severity as well as blood pressure and symptoms in patients with atrial fibrillation. Additionally, interrogation of CPAP efficacy, adherence and side effects should be implemented in the regular assessment of patients treated with CPAP.

In conclusion, OSA is highly prevalent in patients with CV comorbidities. Despite the absence of a clear evidence that systematic treatment of OSA can prevent secondary CV events, OSA management is recommended to control blood pressure and sinus rhythm. Testing for and treatment of OSA can be best organized within an integrated care pathway with a close and interdisciplinary collaboration between the sleep specialist, cardiologist/nephrologist and specialized nurses. 
Table Randomised trials of OSA treatment with CPAP therapy in patients with cardiovascular disease: entry criteria, number of patients, mean follow-up, primary results, and results of subgroup analysis of higher adherence subgroup.

\begin{tabular}{|c|c|c|c|c|c|c|}
\hline Trial & Patient group & $\begin{array}{l}\text { OSA } \\
\text { diagnosis }\end{array}$ & $\begin{array}{l}\text { Intervention } \\
\text { (patient } \\
\text { numbers) }\end{array}$ & $\begin{array}{l}\text { Follow-up } \\
\text { (mean) }\end{array}$ & $\begin{array}{l}\text { Primary } \\
\text { outcome } \\
\text { (MACE) }\end{array}$ & $\begin{array}{l}\text { Daytime } \\
\text { sleepiness } \\
\text { at baseline }\end{array}$ \\
\hline SAVE & Prevalent CVD & ODI>12/h & $\begin{array}{l}\text { CPAP v control } \\
(1346 / 1341)\end{array}$ & 43 months & $\begin{array}{l}\text { HR } 1.10(95 \% \\
\text { CI } 0.91-1.32)\end{array}$ & $\begin{array}{l}\text { ESS < } 15 \\
\text { Severe } \\
\text { sleepiness } \\
\text { excluded }\end{array}$ \\
\hline RICCADSA & $\begin{array}{l}\text { Revascularised } \\
\text { CVD }\end{array}$ & $\mathrm{AHI}>15 / \mathrm{h}$ & $\begin{array}{l}\text { CPAP v control } \\
(122 / 122)\end{array}$ & 57 months & $\begin{array}{l}\text { HR } 0.80(95 \% \\
\text { Cl } 0.46-1.41)\end{array}$ & $\begin{array}{l}\text { ESS }<10 \\
\text { Non sleepy }\end{array}$ \\
\hline ISAAC & $\begin{array}{l}\text { Acute coronary } \\
\text { syndrome }\end{array}$ & $\mathrm{AHI}>15 / \mathrm{h}$ & $\begin{array}{l}\text { CPAP v control } \\
(631 / 631)\end{array}$ & 40 months & $\begin{array}{l}\text { HR } 0.89(95 \% \\
\text { Cl } 0.68-1.17)\end{array}$ & $\begin{array}{l}\text { ESS }<10 \\
\text { Non sleepy }\end{array}$ \\
\hline
\end{tabular}

AHI: apnea-hypopnea index; CPAP: continuous positive airway pressure; CVD: cardiovascular disease; ESS: Epworth Sleepiness Scale; MACE: major adverse cardiovascular events; ODI: oxygen desaturation index; OSA: obstructive sleep apnea

Figure

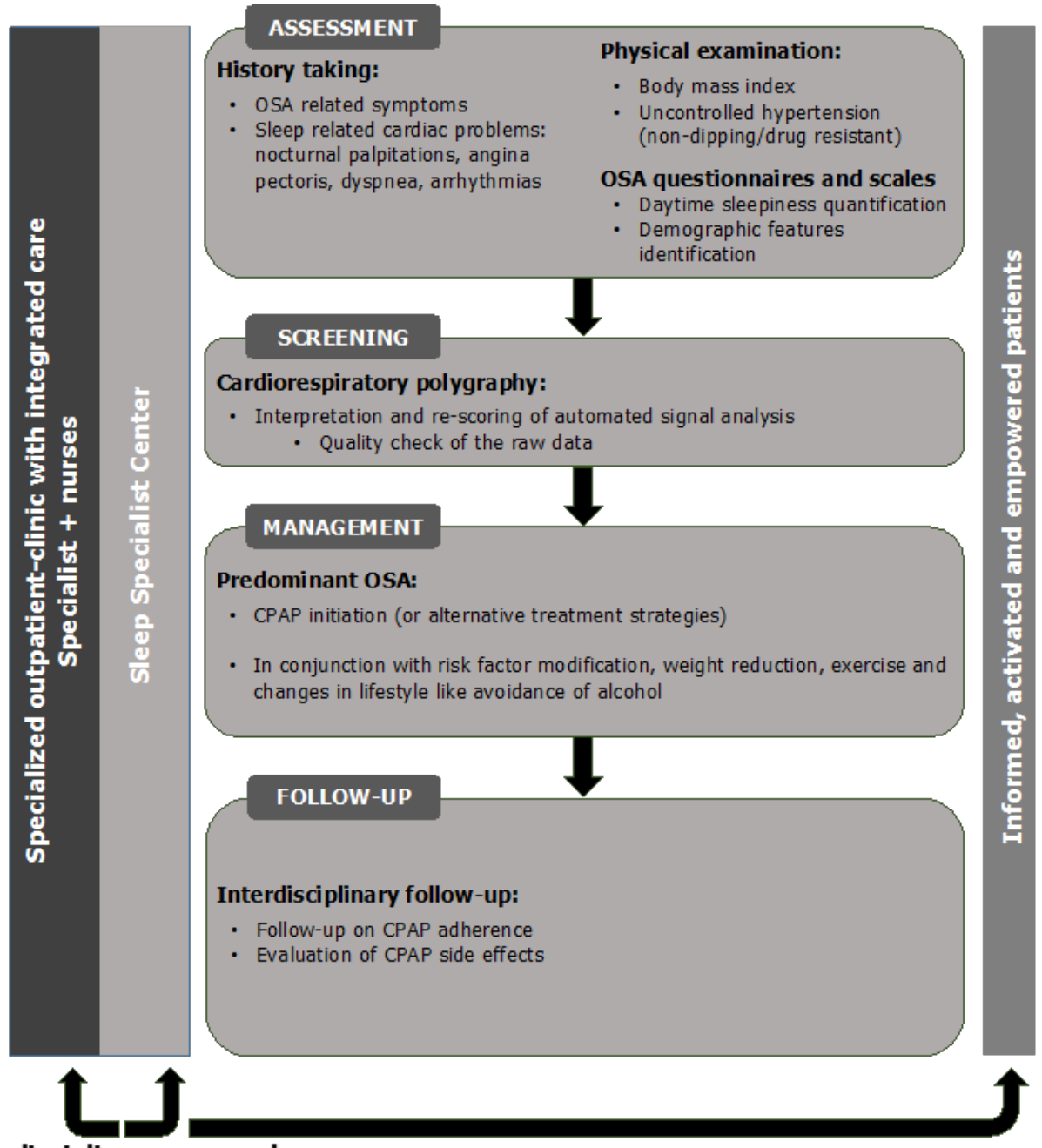




\section{References:}

1.Linz D, Woehrle $H$, Bitter $T$, Fox $H$, Cowie MR, Böhm M, Oldenburg $\mathrm{O}$. The importance of sleepdisordered breathing in cardiovascular disease. Clin Res Cardiol. 2015;104:705-718. DOI: 10.1007/ s00392-015-0859-7

2.Johnson DA, Thomas SJ, Abdalla M et al. Association Between Sleep Apnea and Blood Pressure Control Among Blacks. Circulation 2019;139:1275-1284. DOI: 10.1161/CIRCULATIONAHA.118.036675

3.Liu L, Cao Q, Guo Z, Dai Q. Continuous Positive Airway Pressure in Patients With Obstructive Sleep Apnea and Resistant Hypertension: A Meta-Analysis of Randomized Controlled Trials. J Clin Hypertens 2016;18:153-158. DOl: 10.1111/jch.12639

4.Linz D, McEvoy RD, Cowie MR et al. Associations of Obstructive Sleep Apnea With Atrial Fibrillation and Continuous Positive Airway Pressure Treatment: A Review. JAMA Cardiol 2018;3:532-54 DOl: 10.1001/ jamacardio.2018.0095

5.McEvoy RD, Antic NA, Heeley E et al. CPAP for prevention of cardiovascular events in obstructive sleep apnea. N Engl J Med 2016;375:919-931. DOl: 10.1056/NEJMoa1606599

6.Peker Y, Glantz H, Eulenburg C et al. Effect of positive airway pressure on cardiovascular outcomes in coronary artery disease patients with non-sleepy obstructive sleep apnea. The RICCADSA randomised controlled trial. Am J Resp Crit Care Med 2016;194:613-620. DOl: 10.1080/14017430802276106

7.Sanchez-de-la-Torre M, Sanchez-de-la-Torre A, Bertran S et al. Effect of obstructive sleep apnoea and its treatment with continuous positive airway pressure on the presence of cardiovascular events in patients with acure coronary syndrome (ISAAC study): a randomised controlled trial. Lancet Respir Med 2020;8:359-367. DOI: 10.1016/ S2213-2600(19)30271-1

8.Williams B, Mancia G, Spiering W, Agabiti Rosei E, Azizi M, Burnier M, Clement DL, Coca A, de Simone G, Dominiczak A, Kahan T, Mahfoud F, Redon J, Ruilope L, Zanchetti A, Kerins M, Kjeldsen SE, Kreutz R, Laurent S, Lip GYH, McManus R, Narkiewicz K, Ruschitzka F, Schmieder RE, Shlyakhto E, Tsioufis C, Aboyans V, Desormais I; ESC Scientific Document Group. 2018 ESC/ESH Guidelines for the management of arterial hypertension. Eur Heart J. 2018;39:3021-3104. DOI: 10.1093/eurheartj/ehy339

9. Hindricks G, Potpara T, Dagres N, Arbelo E, Bax JJ, Blomström-Lundqvist C, Boriani G, Castella M, Dan GA, Dilaveris PE, Fauchier L, Filippatos G, Kalman JM, La Meir M, Lane DA, Lebeau JP, Lettino M, Lip GYH, Pinto FJ, Thomas GN, Valgimigli M, Van Gelder IC, Van Putte BP, Watkins CL; ESC Scientific Document Group. 2020 ESC Guidelines for the diagnosis and management of atrial fibrillation developed in collaboration with the European Association for Cardio-Thoracic Surgery (EACTS): The Task Force for the diagnosis and management of atrial fibrillation of the European Society of Cardiology (ESC) Developed with the special contribution of the European Heart Rhythm Association (EHRA) of the ESC. Eur Heart J. 2021;42:373-498. DOl: 10.1093/eurheartj/ehaa612

10.Desteghe L, Hendriks IML, Heidbuchel H, Potpara TS, Lee GA, Linz D. Obstructive sleep apnoea testing and management in atrial fibrillation patients: a joint survey by the European Heart Rhythm Association (EHRA) and the Association of Cardiovascular Nurses and Allied Professions (ACNAP). Europace. 2021. DOI: 10.1093/europace/euab109

Dominik Linz - dominik.linz@mumc.nl

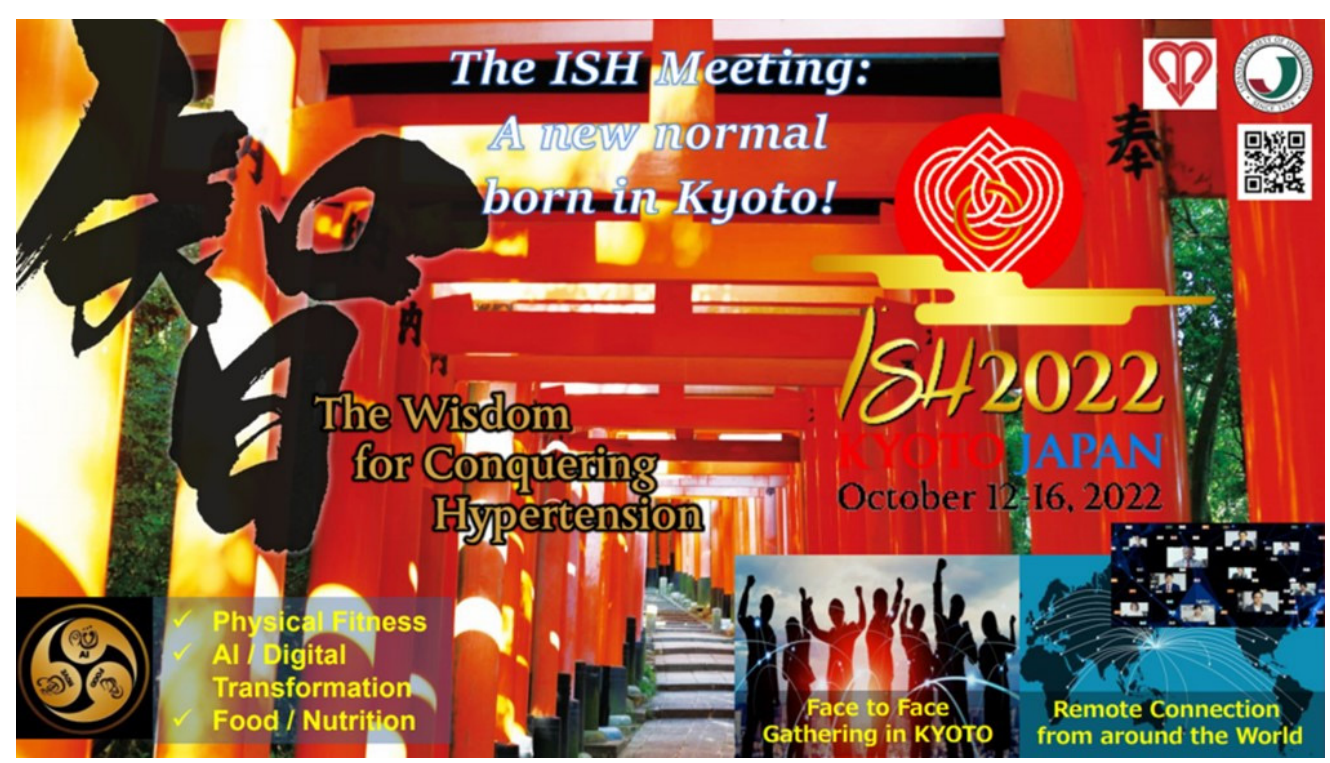

